\title{
Experimental and Numerical Studies of Reduced Fracture Conductivity due to Proppant Embedment in the Shale Reservoir
}

\author{
Junjing Zhang*, ConocoPhillips; Liangchen Ouyang, PetroChina; D. Zhu and A. D. Hill, Texas A\&M University \\ ${ }^{*}$ Corresponding author: Junjing Zhang. Tel: +1 281.658.8143. Fax: +1 832.486.2756 \\ Email: junjing.zhang@conocophillips.com
}

\begin{abstract}
Artificially created fracture networks with sufficient fracture conductivities are essential for economic production from shale reservoirs. Fracture conductivity can be significantly reduced in shale formations due to severe proppant embedment. In addition, proppant embedment induces shale flakes that migrate and clog fracture networks.

A laboratory investigation was performed to understand how excessive proppant embedment caused by the shale-water interaction impairs shale fracture conductivity. The experiments were conducted using Barnett shale samples with representative rock properties. The asperities on the fracture surface were carefully preserved. The damage process was simulated in the laboratory by flowing water through the shale fracture packed with proppants. The water used in the experiments had a similar chemical composition to flowback water in the field. The laboratory results were benchmarked with the results from an experimental study conducted with Berea sandstone samples. Post experimental analysis included microscopic imaging of the fracture surfaces and measurement of the proppant embedment depth.

A computational fluid dynamics study was conducted to quantify the conductivity loss due to proppant embedment on a theoretical basis. We developed pore-scale physical models of the proppant pack and calculated the fracture conductivity loss at different proppant embedment depths. The computation was repeated for a variety of proppant layers. The worst case assumed a $40 \%$ proppant grain volume embedment.

The experimental study showed up to $88 \%$ reduction in fracture conductivity after water flow under 4,000 psi closure stress. The conductivity loss was due to severe proppant embedment as the shale fracture face was softened after its exposure to water. Direct measurement of embedment depths indicated that for fractures that were exposed to water, the average embedment depth was about $50 \%$ of the proppant median diameter, while for fractures that were only exposed to gas, the average embedment depth was just $15 \%$ of the proppant median diameter. It was also observed that pore space of the sand grains at the outlet of the fracture was clogged by shale flakes and fragments. The computational fluid dynamics study proved that even a $10 \%$ proppant grain volume embedment can cause $45 \% \sim 80 \%$ conductivity loss. With the same proppant volume loss due to embedment, the conductivity reduction was less in fractures containing multiple proppant layers than the fracture containing only one layer of proppants.
\end{abstract}

\section{Introduction}

Extensive studies on realistic fracture conductivity were performed during the past half century. Darin and Huitt (1959) believed that a partial monolayer of proppants can obtain high flow capacity and they theoretically derived an equation to calculate fracture conductivity based on the assumption that spherical proppant grains embed into the formation uniformly. Cooke (1973) studied the effect of high-temperature brine, non-Darcy flow and elevated closure stress on fracture conductivity and determined that these factors can reduce fracture conductivities. The conductivity cell that Cooke used in his study is the prototype of the current API conductivity cell. Cooke (1975) carried on his research to investigate the effect of fracturing fluid. $\mathrm{He}$ found that the residue from guar polymer is the most important material in the fracturing fluids that can cause conductivity damage and factors such as proppant concentration, residue of the fracturing fluid, and porosity of the proppant pack determine the conductivity reduction. Following these early works, more studies were done to further understand the damage caused by elevated stress, temperature, fracturing fluid filter cake and fluid additives (Reed 1980; Parker et al. 1987). Fredd et al. (2001) fractured the East Texas Cotton Valley tight sandstone samples and preserved the fracture surface roughness. They measured the conductivities of fractures that were either unpropped or propped by low concentration proppants, and reported that the fracture surface displacement can provide significant unpropped conductivities. Systematic studies on long term fracture conductivity, the impact of fracturing fluid leak-off, gel damage, non-Darcy flow, multiphase flow, proppant crushing and embedment have been done by the Stim-Lab (now a Core-Lab company) Proppant Consortium. Bang et al. (2008) and Yuan (2012) investigated the effective multiphase conductivity loss due to water/condensate block by physical and numerical simulation, and proposed mitigation of liquids block.

The sensitivity of shale to water has been studied in the areas of drilling engineering and formation damage. Common authigenic clay minerals present in petroleum reservoirs are kaolinite, chlorite, illite, smectite and mixed-layer clays (Civan 2007). The movement of ions/water into and out of shale happens in many ways, including convection, osmosis, capillary imbibition, and diffusion (Yan et al. 2013). Differential pressure between the hydraulic fracture and the matrix can cause water movement. However, convective flow into the matrix is limited due to the ultra-low shale matrix permeability and relatively low differential pressure during a fracturing job. When micro-fractures are induced around the embedded proppant in brittle shale rocks (Kassis and Sondergeld 2010), water flows through the fractures under differential pressure. Osmosis is considered as an important mechanism of ion migration into and out of the shale matrix because shale acts as a semi-permeable membrane 
(Low and Anderson 1958). The osmotic efficiency of clay depends on its porosity, salinity, cation exchange capacity and confining pressure (Fritz and Marine 1983; Mody and Hale 1993). Capillary pressure is the pressure difference across the interface between two immiscible fluids. It is a function of interfacial tension, contact angle and the effective radius. Chenevert and Sharma (1993) believed that the driving force of water movement can be best described by the concept of total aqueous potential differences between shale water and injected water.

In recent years, conductivity damage due to clay-water interaction has been brought into attention due to hydraulic fracturing in shale formations. During pre-fracturing formation evaluation in shale, an unpropped fracture conductivity test (UFCT) is sometimes done to determine residual fracture conductivity in the shale rock and different fluid sensitivity. In this test, a horizontal fracture along the shale rock bedding plane is induced in a 1 inch core plug. $\mathrm{KCl}$ and $\mathrm{NaCl}$ at various concentrations as well as fresh water are injected into the fracture (Ramurthy et al. 2011). This experiment is also run to determine the differential pressure needed to allow the liquid to flow in the fracture.

There are limited studies on the conductivity impairment by water for propped fractures under realistic proppant concentrations in shale formations. The water damage mechanisms are yet to be reported with sound laboratory evidence. This work aims at investigating the causes for significant conductivity reduction after water flow in shale reservoirs using both experimental and numerical methods.

\section{Experiment Description}

Shale Sample. The Barnett shale formation was deposited throughout the Fort Worth Basin and tends to thin towards the Llano Uplift in the south with thickness ranging between $30 \mathrm{ft}$ and $50 \mathrm{ft}$ where the outcrop samples were collected (Papazis 2005; Zhang et al. 2013a). According to X-ray Diffraction tests, the outcrop samples in this study contain $31 \%$ quartz, $32 \%$ illite, 9\% mixed layered illite-smectite and 5\% kaolinite (Table 1). Another mineral in the Barnett shale outcrop is anhydrite, which is the main natural fracture infill material (Zhang et al. 2013a). The samples were cut into dimensions fit for the modified API conductivity cell. Due to thickness limitation of the outcrop samples, sandstones were cut to make the $1 \sim 1.5$ inch thick shale samples up to 3 inches which is required by the modified API conductivity cell (Fig. 1).

Fluids and Proppants. Industrial grade dry nitrogen was used to measure the undamaged fracture conductivity and the recovered fracture conductivity after water damage. Brine with a similar chemical composition to typical flowback water was injected into the fracture after nitrogen to simulate the damage process. A typical flowback water sample in the Barnett shale has total dissolved solids (TDS) of 39,000 mg/L (Horner 2011). In this study, we formulated the brine with total dissolved solids of 38,000 mg/L (Table 2). 40/70 mesh Badger sand was used in this study. Some quality parameters of the proppants are shown in Table 3. Sieve analysis was done to understand the particle size distribution (Fig. 2).

Experimental setup. The entire apparatus consists of five separate units: (1) gas injection unit; (2) liquid injection unit; (3) conductivity cell assembly; (4) closure stress application unit; and (5) pressure/rate data acquisition unit.

The schematic of the setup is shown in Fig. 3. The gas injection unit consists of a nitrogen tank containing industrial grade dry nitrogen and a pressure regulator. The liquid injection unit includes a 1000D Teledyne ISCO Syringe pump, a PVC refilling accumulator, two stainless steel displacement accumulators, an AW-32 hydraulic oil reservoir and the flow line manifolds. The 1000D Teledyne syringe pump has one liter nominal capacity. The flow rate range for this pump is $0.1 \sim 408$ $\mathrm{mL} / \mathrm{min}$ and the working pressure is $0 \sim 2,000$ psi. In Fig. 3, the parts highlighted in orange are only in contact with AW-32 hydraulic oil. All other aspects of the modified conductivity cell are designed as per the API conductivity cell except the dimensions. The modified API conductivity cell accommodates 6 inches thick rock samples. The hydraulic load frame can apply 208,000 lbf at the rate of 1,215 lbf/min (stress rate $100 \mathrm{psi} / \mathrm{min}$ ). The position sensor of the load frame has an accuracy of $4 \times 10^{-4}$ inch. The gas flow controller has a full range of $0.35 \mathrm{ft}^{3} / \mathrm{min}$ with an accuracy of $3.5 \times 10^{-5} \mathrm{ft}^{3} / \mathrm{min}$. Differential pressure sensor diaphragms can be switched and the pressure ratings used in this study are 5 psi and 20 psi.

Experimental procedures and conditions. To evaluate the conductivity damage, both gas and water were flowed through the fracture. Dry nitrogen was flowed first to measure the undamaged fracture conductivity since nitrogen does not react with shale. Then, water was injected into the fracture to soak the shale fracture faces until the steady state flow was reached. Finally, dry nitrogen was flowed again to remove water from the fracture and to measure the recovered fracture conductivity. Severity of conductivity damage by water was assessed by comparing the two gas-measured conductivities.

Experiments were run at $70{ }^{\circ} \mathrm{F}$. Both proppants and shale samples were kept dry before experiment. The undamaged fracture conductivity was measured in the short-term experiment as per API RP-61. Water was injected at the higher rate (0.5 $\mathrm{mL} / \mathrm{min})$ to saturate the system and then at the lower rate $(0.1 \mathrm{~mL} / \mathrm{min})$ until the flow stabilized. The second gas flow removed water from the fracture by displacement and evaporation. Gas flowed through the fracture until the steady state regime appeared. The effective closure stress acting on the fracture was set at 4,000 psi. Calculation of the effective closure stress can be found in Zhang et al. (2013a).

Post-experimental analysis. Images of the fracture faces were taken after the experiments using a Zeiss Axiophot microscope. An experiment where the shale samples were only exposed to dry gas was also run. Direct comparison of the 
fracture faces between the samples exposed to water and only to dry gas was made first; then a quantitative evaluation of the proppant embedment with and without exposure to water was performed.

\section{Numerical Methodology}

A series of numerical simulation cases to study the effect of proppant embedment on the conductivity reduction were performed. The conductivity reduction due to proppant embedment was modeled with a computational fluid dynamics approach. Recently, pore-scale models in CFD have been widely used in studying fluid flow through porous media (Jiang and Lu 2005; Xu and Jiang 2008; Ouyang et al. 2013). We used the CFD software package FLUENT (ANSYS Inc.) in this work. It can account for complicated pore scale geometries, and is cost effective for large computations.

Governing equations. FLUENT uses the finite-volume method to solve the three-dimensional Navier-Stokes equations. Consistent with the experimental conditions for conductivity measurements, the flow was steady state and under $70{ }^{\circ} \mathrm{F}$. The continuity and momentum balance equations for the steady state flow are shown below.

Continuity equation

$$
\frac{\partial u}{\partial x}+\frac{\partial v}{\partial y}+\frac{\partial w}{\partial z}=0
$$

Momentum equations

$$
\begin{aligned}
& \rho\left(u \frac{\partial u}{\partial x}+v \frac{\partial u}{\partial y}+w \frac{\partial u}{\partial z}\right)=\frac{\partial P}{\partial x}+\mu\left(\frac{\partial^{2} u}{\partial x^{2}}+\frac{\partial^{2} u}{\partial y^{2}}+\frac{\partial^{2} u}{\partial z^{2}}\right) \\
& \rho\left(u \frac{\partial v}{\partial x}+v \frac{\partial v}{\partial y}+w \frac{\partial v}{\partial z}\right)=\frac{\partial P}{\partial y}+\mu\left(\frac{\partial^{2} v}{\partial x^{2}}+\frac{\partial^{2} v}{\partial y^{2}}+\frac{\partial^{2} v}{\partial z^{2}}\right) \\
& \rho\left(u \frac{\partial w}{\partial x}+v \frac{\partial w}{\partial y}+w \frac{\partial w}{\partial z}\right)=\frac{\partial P}{\partial z}+\mu\left(\frac{\partial^{2} w}{\partial x^{2}}+\frac{\partial^{2} w}{\partial y^{2}}+\frac{\partial^{2} w}{\partial z^{2}}\right)
\end{aligned}
$$

Computational domain. Computationally, numerical simulation of fluid flow inside the field scale fracture geometry using CFD exceeds the capacity of most computers. To reduce the computational load but still keep the simulations representative, the computational domain shown in Fig. 4(a) was used. Besides the three layers of proppants, the domain also contains an entrance and an exit region of four proppant diameters length on each side. The extended regions are to avoid the impact of inflow and outflow on calculated results and to reduce the possibility of counter-flow during the computation. The proppant particles are arranged in body centered cubic pattern as shown in Fig. 4(b). They form a homogeneous and uniform porous media packing. Four different proppant sizes (20 mesh, 40 mesh, 70 mesh and 100 mesh) are used in order to study the effect of proppant size on fracture conductivity. To mimic the realistic situation, the surfaces of adjacent proppants have finite contact points. Gas flows from left to right. The top and bottom surfaces represent the shale fracture boundaries. The domain is created by GAMBIT (ANSYS Inc.), a general-purpose preprocessing CFD software used to generate flow geometry and meshes.

Proppant embedment into the shale fracture surface happens with increasing effective closure stress, and is worsened due to fracture surface softening by water. This phenomenon has been represented in the model, as shown in Fig. 5. In Fig. 5(a) and (c), proppants of the top and bottom layers are truncated because embedment into the shale fracture surfaces has occurred. To investigate how the loss of flow area influences the overall fracture conductivity, we modeled multiple cases for one, two and three layers of proppants. $40 \%$ of the proppant grain volume is lost due to embedment in the case where the maximum simulated embedment happens.

Numerical setup. Grid size affects the accuracy of the numerical simulation. We conducted a series of calculations with different grid sizes to check the computational stability and accuracy. To keep a balance between accuracy and efficiency, the grid size of $0.02 \mathrm{~mm}$ in the $\mathrm{x}, \mathrm{y}$, and $\mathrm{z}$-directions was chosen in all computational cases. Additionally, the numerical simulation cases using a grid size of $0.02 \mathrm{~mm}$ did not have any instability problems.

The numerical simulations assumed that the flow was three-dimensional, single-phase and laminar. The second-order upwind scheme was adopted for the spatial discretization of flow pressure and momentum governing equations. The gradient of spatial discretization was based on Green-Gauss Cell. To couple the pressure and the velocity, the Semi-Implicit Method for Pressure Linked Equations (SIMPLE) algorithm was used (Patankar 1980). A constant velocity boundary condition was imposed at the inlet. A constant zero static pressure condition was used at the outlet, which was relative to the reference cell 
pressure of 50 psi. Wall boundary conditions were set on the shale surfaces as well as the proppant surfaces as shown in Fig. 4(a). The symmetrical boundary condition was used in the Z direction in Fig. 5(c) to keep periodicity in the cell width direction. The solution was assumed to have converged when the root mean square of the normalized residual error reached $10^{-9}$. The cases were run on an IBM iDataplex Cluster with nodes based on Intel's 64-bit Nehalem \& Westmere processor.

\section{Results and Discussions}

Fracture conductivities of Barnett shale samples were measured by gas before and after the water injection. To benchmark the measurements, fracture conductivities of Berea sandstone samples were also measured under the same experimental conditions. Finally, fracture conductivity reductions due to proppant embedment were calculated using the numerical model to verify the experimental results.

Conductivities in Barnett shale. The fracture was propped by $40 / 70$ mesh sands at an areal concentration of $0.10 \mathrm{lb} / \mathrm{ft}^{2}$. The closure stress was constant at 4,000 psi throughout the experiment. Results are shown in Fig. 6. After the initial measurement by gas, fracture conductivity kept dropping as water was injected displacing gas out of the fracture. After 2 hours of water injection at the rate of $0.1 \mathrm{~mL} / \mathrm{min}$, the flow reached steady state where the fracture conductivity was calculated. The process of water removal by gas includes two stages: (1) water displacement by gas and (2) evaporation of water. The latter stage is also referred to as "flow-through drying" in porous media (Mahadevan and Sharma 2003; Zhang et al. 2013b). The two-stage water removal is reflected in the recovered conductivity curve after 370 minutes. The fast conductivity recovery before 380 minutes represents the displacement process. During this phase, we observed a continuous water stream for a short period followed by large water droplets coming from the outlet of the flowline. After that, it enters the long evaporation process where the conductivity is recovered slowly until the steady flow condition is reached. During this phase, no large water droplets were seen. The long term gas flow dries the fracture surface so that single phase gas flows through the fracture.

The initial undamaged conductivity for the shale fracture is $15 \mathrm{md}-\mathrm{ft}$, which is significantly reduced to $0.41 \mathrm{md}-\mathrm{ft}$ after the water flow. The gas flow can only recover the fracture conductivity to $1.7 \mathrm{md}-\mathrm{ft}$. Due to the water flow, there is an $88 \%$ unrecoverable conductivity loss at the end of the experiment. Longer term rock creep and proppant rearrangement play an important role in fracture conductivity measurement over time. Zhang et al. (2014) found out that in the first 20 hours fracture conductivity can be reduced by $20 \%$ under the same experimental conditions while the conductivity variation is negligible in the following 30 hours.

More experiments were conducted under the same conditions and similar trends were observed.

Conductivities in Berea sandstone. Quartz comprises up to $87 \%$ of the Berea sandstone and clay only accounts for $6 \%$ as shown in Table 4. The same procedures and experimental conditions were applied in the conductivity measurements of sandstone samples. Results are shown in Fig. 7. In this plot, conductivities of Barnett shale samples are from Fig. 6. The initial undamaged fracture conductivity using Berea sandstone samples is $65 \mathrm{md}-\mathrm{ft}$. After water flow, the recovered fracture conductivity by gas is $61 \mathrm{md}-\mathrm{ft}$. The $94 \%$ conductivity recovery after water flow indicates that there is negligible damage to conductivity by water in the Berea sandstone fracture.

Comparison of the fracture conductivities of Barnett shale samples with Berea sandstone samples clearly suggests that the rock lithology has a significant impact on the recovered fracture conductivity. The clay-water interaction results in severe damage to fracture conductivity in shale.

Shale fracture surface softening. Experimental results show that $88 \%$ of the undamaged fracture conductivity is permanently lost in Barnett shale samples. Significant conductivity loss can be attributed to the excessive proppant embedment due to the shale fracture surface softening.

Microscopic images of proppant embedment were taken for both experiments with and without water flow. Fig. 8(a) shows the "moon-surface-like" image of a shale fracture face under oblique light after the water experiment. The embedment craters congregate on the fracture surface next to each other. In Fig. 8(b), some proppants are completely buried into the fracture face. Fig. 9 shows the Barnett shale fracture that is only exposed to gas during the conductivity measurement. Obviously, the embedment is much less and shallower than the fracture exposed to water.

Proppant embedment depth was then measured by a microscope at five locations spaced by one inch (Fig. 10). At each location, multiple embedment depths were measured. This image also highlights the fracture surface roughness. The red and blue regions represent the surface hills and valleys respectively. During the measurement, the focus of the microscope was adjusted from the bottom of the embedment crater to the surrounding by an increment of $10 \mu \mathrm{m}$. The embedment depth was also measured in the experiment where only gas was flowed. The comparison is shown in Fig. 11.

The average embedment depth for the fracture surface after water flow is about $140 \mu \mathrm{m}$, while the average embedment depth for the fracture only exposed to gas is just $40 \mu \mathrm{m}$. The median diameter of $40 / 70$ mesh sand is $300 \mu \mathrm{m}$. This means, on average, half of the sand grain is buried into the fracture face after it is exposed to water due to the shale surface softening.

Shale softening by water has been studied to overcome the challenges in drilling through shale formations. Shale-water interaction in the reservoir leads to reduced effective stress, Young's modulus, uniaxial compressive strength and eventually causes rock failure (Chenevert and Sharma 1993; Chen and Ewy 2002; Lin and Lai 2013). When water migrates into clay structure, the local pore pressure is increased. The excessive pore pressure is hard to dissipate due to the ultra-low permeability 
of the shale matrix (Zhang 2005). Therefore, the effective stress of the shale matrix where the water front has reached is reduced. This localized pore pressure increment due to water movement is called "undrained condition" (Detournay and Cheng 1988). Migrated water in the clay lattice causes clay expansion and reduces the interlayer bonding strength of clay (Zhang 2005). The combination of elevated local pore pressure and reduced strength leads to the softening of shale after being soaked in water.

Fracture conductivities calculated by the numerical model. In the numerical study, a large range of fracture conditions were investigated. The proppant diameter was varied from $149 \mu \mathrm{m}$ to $840 \mu \mathrm{m}$ (100 mesh to 20 mesh) and the fraction of the proppant grain embedment volume was varied from 0 to 0.4 . Conductivities of fractures propped by one, two and three layers of proppants were calculated respectively. The results are shown in Fig. 12. Obviously, fracture conductivities are affected by the proppant size, the embedment volume ratio and the number of proppant layers. As shown in Fig. 12(a), for one layer of proppants without embedment, fracture conductivity of 20 mesh proppants is 1406 md-ft while the conductivity of 100 mesh proppants is only $7.8 \mathrm{md}-\mathrm{ft}$ under the same conditions. For one layer of 20 mesh proppants, the conductivity drops from 1406 md-ft to 8.3 md-ft when the grain embedment volume ratio increases from 0 to 0.4 . The conductivities of two layers and three layers of proppants are significantly improved comparing with just one layer of proppants under the same flow conditions as shown in Fig. 12(b) and (c).

Effect of proppant embedment and number of layers. Fig. 13 shows the grain embedment volume ratio versus the ratio of remaining fracture conductivity for various proppant layers. It can be seen that for a monolayer proppant pack, the fracture conductivity decreases dramatically as the embedment volume ratio increases. As the volume ratio reaches $0.4,99.4 \%$ of the conductivity is lost due to the flow area loss by proppant embedment. This illustrates that proppant embedment can be a major cause for significant shale fracture conductivity loss when low concentration proppant stages are pumped, because monolayer proppant packs are more likely to be created. Two or more layers of proppants can greatly impede the conductivity reduction as a result of proppant embedment. This is because in multiple proppant layers, the conductivity depends more on the internal cleaner proppant pack and less on the flow areas adjacent to the fracture walls.

The huge reduction in fracture conductivity at the first $10 \%$ proppant grain volume loss can be illustrated by Fig. 14. The location near the shale fracture has more open space for fluid flow than the location in the middle, as highlighted in red in Fig. 14(b). For a given grain volume loss due to embedment, there is greater embedment depth in the early embedment phase than the later phase because of the spherical shape of the proppant.

\section{Conclusions}

We have conducted a laboratory study on the mechanism of shale fracture conductivity damage caused by shale-water interactions. Pore scale numerical models were built to enhance the understanding of the effect of proppant embedment on shale fracture conductivity reduction. Based on the experimental and numerical studies, the following conclusions are made.

1. Up to $88 \%$ of the undamaged shale fracture conductivity was lost after water flow in the Barnett shale under 4,000 psi closure stress. The significant conductivity loss was caused by the shale fracture surface softening after its exposure to water.

2. The average embedment depth was about $50 \%$ of the proppant median diameter in fractures that were exposed to water, while the average embedment depth was just $15 \%$ of the proppant median diameter in fractures that were only exposed to gas.

3. The computational fluid dynamics study showed that the first $10 \%$ of proppant grain embedment volume can cause a significant conductivity reduction $(45 \% \sim 80 \%)$ depending on the number of proppant layers. Given the same proppant volume loss due to embedment, the conductivity reduction was less in fractures containing multiple proppant layers because with multiple layers of proppants, the fracture conductivity depends more on the internal, cleaner proppants and less on the flow areas adjacent to the fracture walls.

4. The numerical study indicated that fractures propped by a monolayer of proppants experienced severe conductivity reduction due to the large loss of flow area even at a small grain embedment volume.

5. The pore scale numerical model was able to capture the flow characteristics inside the proppant pack. It proved to be a useful tool for studying the flow behavior including conductivity creation and impairment in hydraulic fractures.

\section{Nomenclature}

$x, y, z \quad$ Indices for dimensions

$u \quad$ Velocity in $x$ direction

$v \quad$ Velocity in $y$ direction

$w \quad$ Velocity in $z$ direction

$p \quad$ Pressure inside the fracture 


\section{Acknowledgement}

The authors would like to acknowledge the sponsors of Crisman Institute for Petroleum Research in the Petroleum Engineering Department at Texas A\&M University as well as the Department of Energy, and the Research Partnership to Secure Energy for America (RPSEA) for their support of this work (RPSEA project 11122-07-TAMU-Zhu).

\section{References}

1. ANSYS FLUENT User's Guide, Release 13.0. ANSYS Inc., Canonsburg, PA 2010.

2. ANSYS GAMBIT User's Guide, Release 2.3. ANSYS Inc., Canonsburg, PA 2006.

3. Bang, V., Yuan, C., Pope, G.A., Sharma, M.M., Baran, R. Jr., Skildum, J. and Linnemeyer, H.C. 2008. Improving Productivity of Hydraulically Fractured Gas Condensate Wells by Chemical Treatment. Paper OTC 19599 presented at the SPE Offshore Technology Conference held in Houston, Texas, U.S. A., 5-8 May.

4. Chen, G. and Ewy, R.T. 2002. Investigation of the Undrained Loading Effect and Chemical Effect on Shale Stability. Paper SPE 78164 presented at the SPE/ISRM Rock Mechanics Conference, Irving, Texas, U.S.A., 20-23 October.

5. Chenevert M.E. and Sharma A.K. 1993. Permeability and Effective Pore Pressure of Shales. SPE Drilling \& Completion, 8(1): 28-34.

6. Civan, F. 2007. Reservoir Formation Damage. Houston, Texas: Gulf Publishing Company.

7. Cooke Jr. C.E. 1973. Conductivity of Fracture Proppants in Multiple Layers. Journal of Petroleum Technology, 25(9): 1101-1107.

8. Cooke Jr. C.E. 1975. Effect of Fracturing Fluids on Fracture Conductivity. Journal of Petroleum Technology, 27(10): 1273-1282.

9. Darin, S.R. and Huitt, J.L. 1959. Effect of a Partial Monolayer of Proppant Agent on Fracture Flow Capacity. Paper SPE 1291 presented at the Annual Fall Meeting, Dallas, Texas, U.S.A., 4-7 October.

10. Detournay, E. and Cheng, A.H-D. 1988. Poroelastic Response of a Borehole in a Non-Hydrostatic Stress field. International Journal of Rock Mechanics and Mining Sciences, 25(3): 171-182.

11. Fredd, C.N., McConnell, S.B., Boney, C.L., and England, K.W. 2001. Experimental Study of Fracture Conductivity for Water-Fracturing and Conventional Fracturing Applications. SPE Journal, 6(3): 288-298.

12. Fritz, S.J. and Marine, I.W. 1983. Experimental Support for a Predictive Osmotic Model of Clay Membranes. Geochemistry Cosmochim, ACTA, 47(8): 1515-1522.

13. Horner, P., Halldorson, B., and Slutz, J.A. 2011. Shale Gas Water Treatment Value Chain-A Review of Technologies, including Case Studies. Paper SPE 147264 presented at the SPE Annual Technical Conference and Exhibition, Denver, Colorada, U.S.A., 30 October-2 November.

14. Jiang, P., Lu, X. 2005. Numerical Simulation of Fluid Flow and Convection Heat Transfer in Sintered Porous Plate Channels. International Journal of Heat and Mass Transfer. Volume 49, Number 9-10, Page 1685-1695.

15. Kassis, S. and Sondergeld, C. 2010. Fracture Permeability of Gas Shale: Effects of Roughness, Fracture offset, Proppant, and Effective Stress. Paper SPE 131376 presented at the CPS/SPE International Oil \& Gas Conference and Exhibition, Beijing, China, 8-10 June.

16. Lin, S. and Lai, B. 2013. Experimental Investigation of Water Saturation Effects on Barnett Shale's Geomechanical Behaviors. Paper SPE 166234 presented at the SPE Annual Technical Conference and Exhibition, New Orleans, Louisiana, U.S.A., 30 September-2 October.

17. Low, P.F. and Anderson, D.M. 1958. Osmotic Pressure Equation for Determining Thermodynamic Properties of Soil Water. Soil Science, 86(5): 251-253.

18. Mahadevan, J. and Sharma, M.M. 2003. Clean-up of Water Blocks in Low Permeability Formations. Paper SPE 84216 presented at the SPE Annual Technical Conference and Exhibition, Denver, Colorado, U.S.A., 5-8 October.

19. Mody, F.K. and Hale, A.H. 1993. A Borehole Stability Model to Couple the Mechanics and Chemistry of Drilling Fluid Shale Interaction. Paper SPE/IADC 25728 presented at the 1993 SPE/IADC Drilling Conference, Amsterdam, the Netherlands, 23-25 February.

20. Ouyang, L., Zhu, D. and Hill, A.D. 2013. Effect of Pore Structure on Non-Newtonian Fluid Flow. Paper IPTC 17011 presented at the International Petroleum Technology Conference, Beijing, China, 26-28 March.

21. Papazis, P.K. 2005. Petrographic Characterization of the Barnett Shale, Fort Worth Basin, Texas. MS Thesis. The University of Texas at Austin, Austin, Texas (August 2005).

22. Parker, M.A. and McDaniel, B.W. 1987. Fracturing Treatment Design Improved by Conductivity Measurements Under In-Situ Conditions. Paper SPE 16907 presented at the SPE Annual Technical Conference and Exhibition, Dallas, Texas, U.S.A., 27-30 September.

23. Patankar, S.V. 1980. Numerical Heat Transfer and Fluid Flow. Washington, D.C.: Hemisphere Publishing Corporation.

24. Ramurthy, M., Barree, R.D., Kundert, D.P., Petre, E., and Mullen, M. 2011. Surface-Area vs Conductivity-Type Fracture Treatments in Shale Reservoirs. SPE Production and Operations, 26(4): 357-367.

25. Reed, M.G. 1980. Gravel Pack and Formation Sandstone Dissolution during Steam Injection. Journal of Petroleum Technology, 32(6): 941-949.

26. Xu, R., Jiang, P. 2008. Numerical Simulation of Fluid Flow in Microporous Media. International Journal of Heat and 
Mass Transfer. Volume 29, Number 5, Page 1447-1455.

27. Yan, B., Wang, Y., and Killough, J.E. 2013. Beyond Dual-Porosity Modeling for the Simulation of Complex Flow Mechanisms in Shale Reservoirs. Paper SPE 163651 presented at the SPE Reservoir Simulation Symposium in the Woodlands, Texas, U.S.A., 18-20 February.

28. Yuan, C. 2012. The Chemical Treatment to Remove Liquid Block in Hydraulic Fractured Well-A Simulation Study with Leak-Off. Paper SPE 158190 presented at the 2012 Energy Conference-Developing Resources for Sustainability at Port-of-Spain, Trinidad, 11-13 June.

29. Zhang, J. 2005. The Impact of Shale Properties on Wellbore Stability. PhD dissertation, The University of Texas at Austin, Austin, Texas (August 2005).

30. Zhang, J., Kamenov, A., Zhu, D., and Hill, A.D. 2014. Laboratory Measurement of Hydraulic Fracture Conductivities in the Barnett Shale. SPE Production \& Operations, 29(3): 216-227.

31. Zhang, Q., Zhu, D., and Hill, A.D. 2013. Modeling of Spent-Acid Blockage Damage in Stimulated Gas Wells. Paper IPTC 16481 presented at the International Petroleum Technology Conference in Beijing, China, 26-28 March. 
Table 1-Mineralogy of the Barnett Shale samples by X-Ray Diffraction.

\begin{tabular}{cc}
\hline Quartz & $31 \%$ \\
Feldspar & $2 \%$ \\
Kaolinite & $5 \%$ \\
Illite & $32 \%$ \\
Mixed layered illite-smectite & $9 \%$ \\
Chlorite & $4 \%$ \\
Other & $17 \%$ \\
\hline
\end{tabular}

Table 2-Chemical compositions of the reconstituted water sample in the Barnett shale (Horner 2011).

\begin{tabular}{ccc}
\hline Ions & $\begin{array}{c}\text { Flowback water } \\
(\mathrm{mg} / \mathrm{L})\end{array}$ & Lab $(\mathrm{mg} / \mathrm{L})$ \\
\hline $\mathrm{Na}^{+}$ & 12453 & 12646 \\
$\mathrm{Mg}^{2+}$ & 253 & \\
$\mathrm{Ca}^{2+}$ & 2242 & 2244 \\
$\mathrm{Sr}^{2+}$ & 357 & \\
$\mathrm{Ba}^{2+}$ & 42 & 0.0807 \\
$\mathrm{Mn}^{2+}$ & 44 & 0.0066 \\
$\mathrm{Fe}^{2+}$ & 33 & \\
$\mathrm{SO}_{4}^{2-}$ & 60 & \\
$\mathrm{HCO}_{3}{ }^{-}$ & 289 & 23170 \\
$\mathrm{Cl}^{-}$ & 23797.5 & 38,069 \\
\hline $\mathrm{TDS}^{2+}$ & 39,570 & \\
\hline
\end{tabular}

Table 3-Quality parameters of the proppants.

\begin{tabular}{cccc}
\hline Grain diameter (mm) & $\begin{array}{c}\text { Nephelometric } \\
\text { Turbidity Units (NTU) }\end{array}$ & Roundness & Sphericity \\
\hline $0.149 \sim 0.595$ & 53 & 0.75 & 0.75 \\
\hline
\end{tabular}

Table 4-Mineralogy of the Berea sandstone samples by X-Ray Diffraction.

\begin{tabular}{cc}
\hline Quartz & $87 \%$ \\
Clay & $6 \%$ \\
Carbonate & $2 \%$ \\
Other & $5 \%$ \\
\hline
\end{tabular}




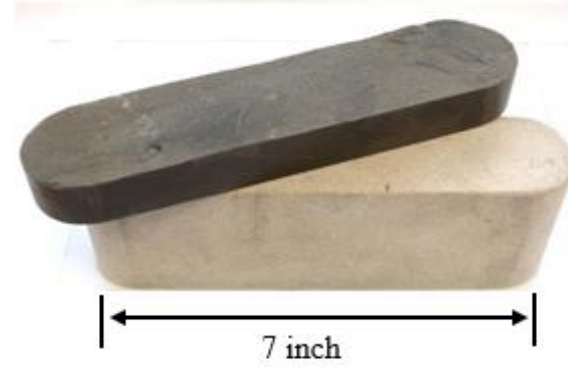

\section{Side B}

Side A

Fig.1-Barnett shale samples shaped to fit into the modified API conductivity cell.

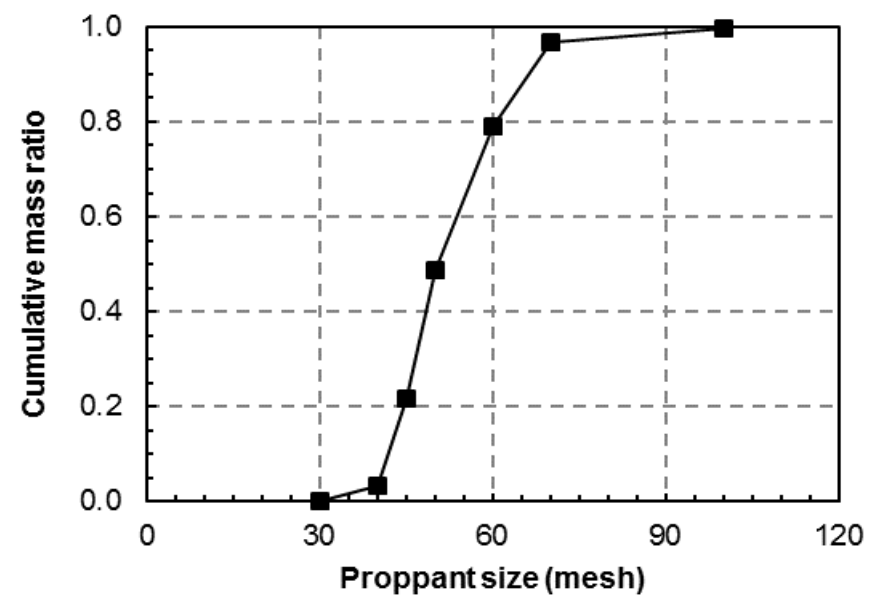

Fig.2-Particle size distribution of $40 / 70$ mesh sands.

\begin{tabular}{l}
\hline$\infty$ Plug valve \\
K Check valve \\
() Pressure gauge/sensor \\
Dack pressure valve \\
— Flow line, $1 / 4$ inch
\end{tabular}

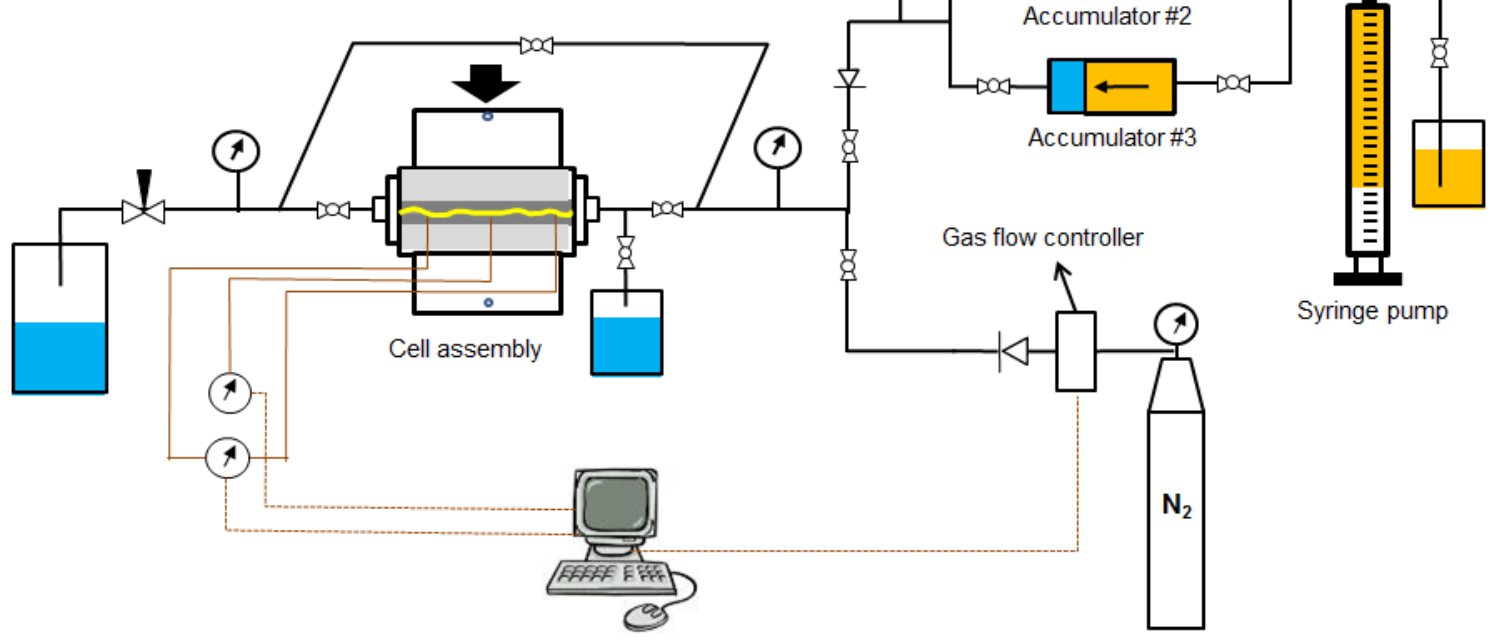

Fig.3-Schematic of the setup to evaluate the conductivity damage by water. 


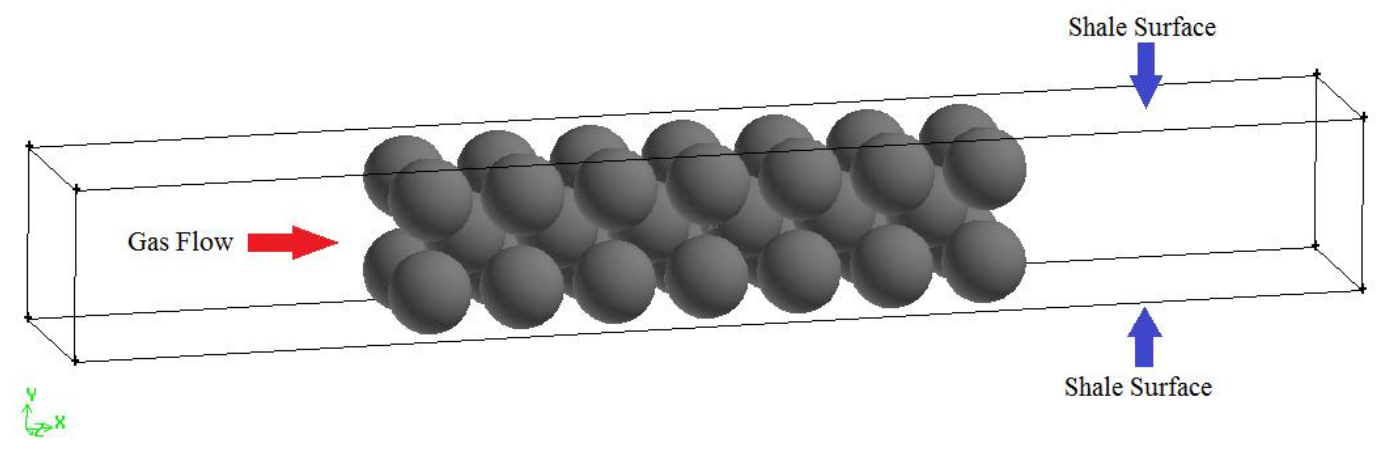

(a)

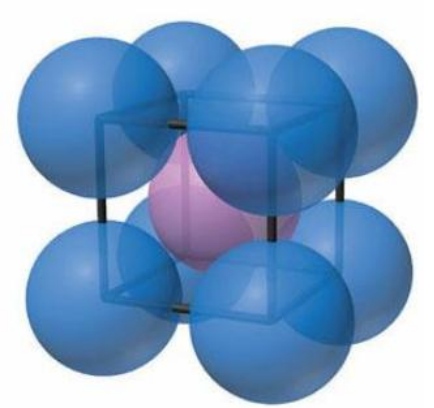

(b)

Fig. 4-(a) Schematic of the computational domain (b) Geometrical pattern for body centered cubic packing.

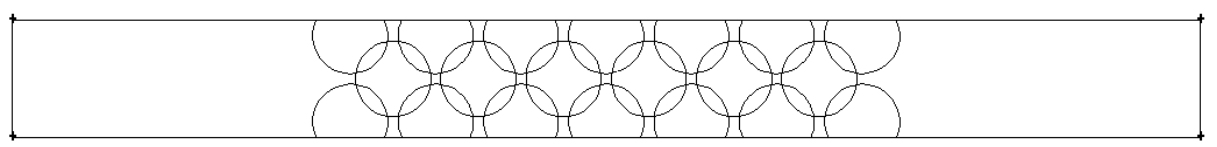

(a) Side View

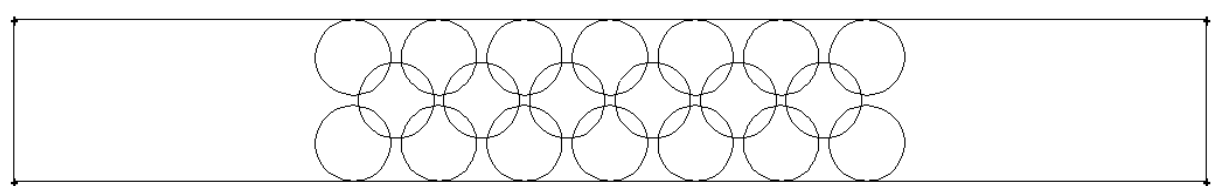

(b) Top View

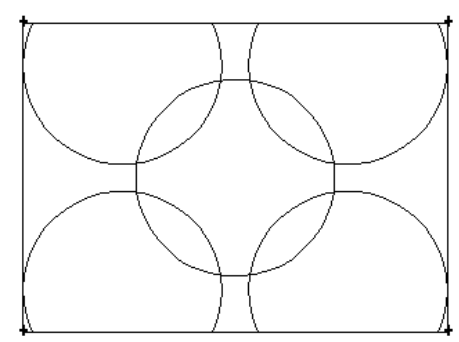

(c) Front View

Fig. 5-Schematics of the proppant embedment into shale fracture surfaces. 


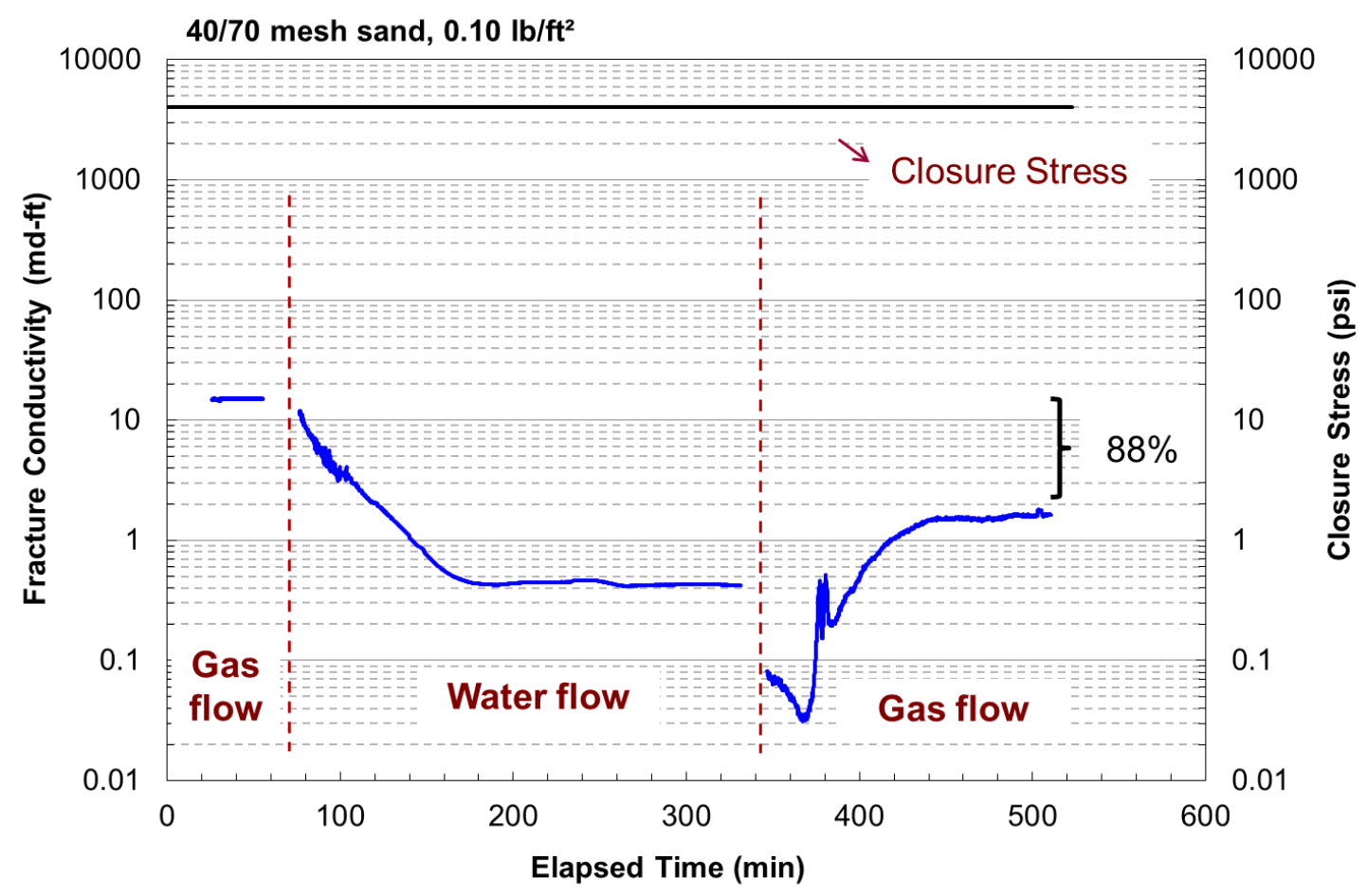

Fig.6-Fracture conductivities of the Barnett shale measured before and after water flow.

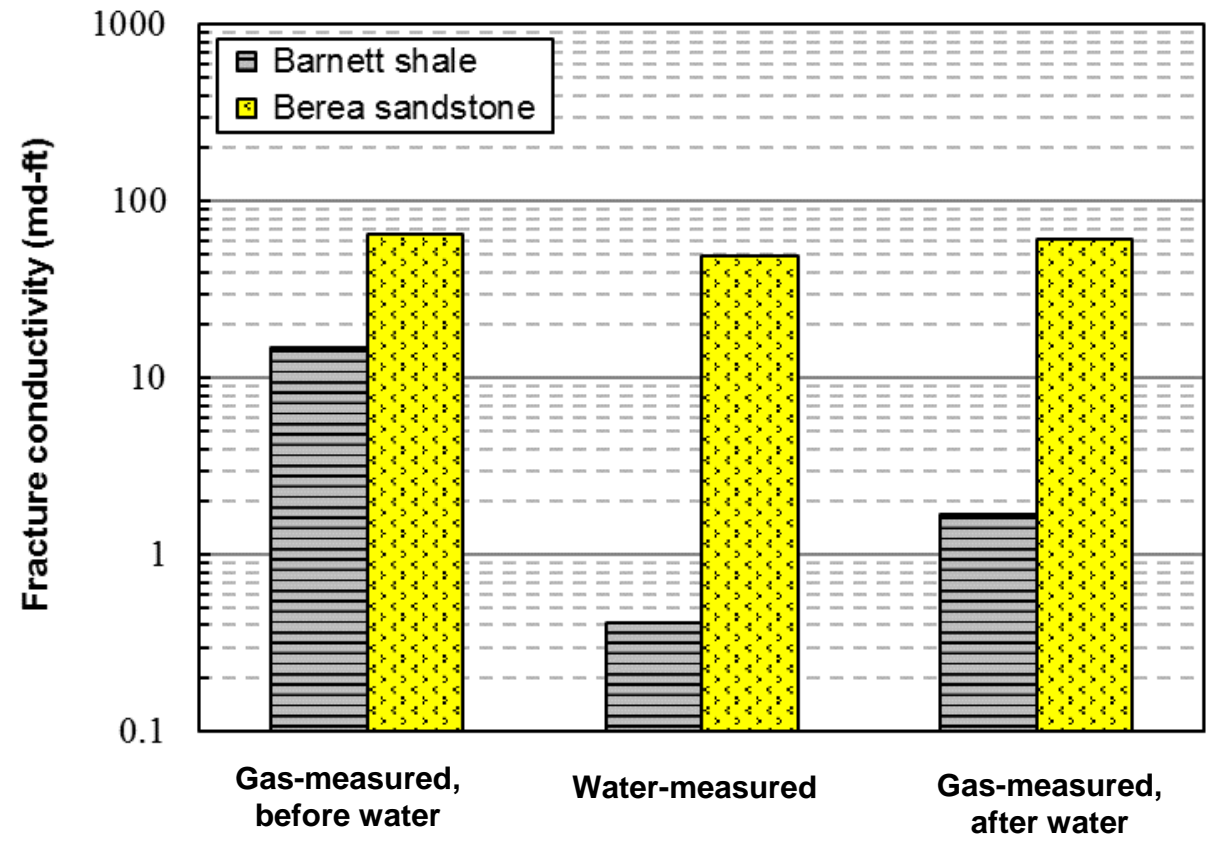

Fig.7-Fracture conductivities of Berea sandstone samples and Barnett shale samples measured before and after water flow. Results of Barnett shale samples are from Fig. 6. 


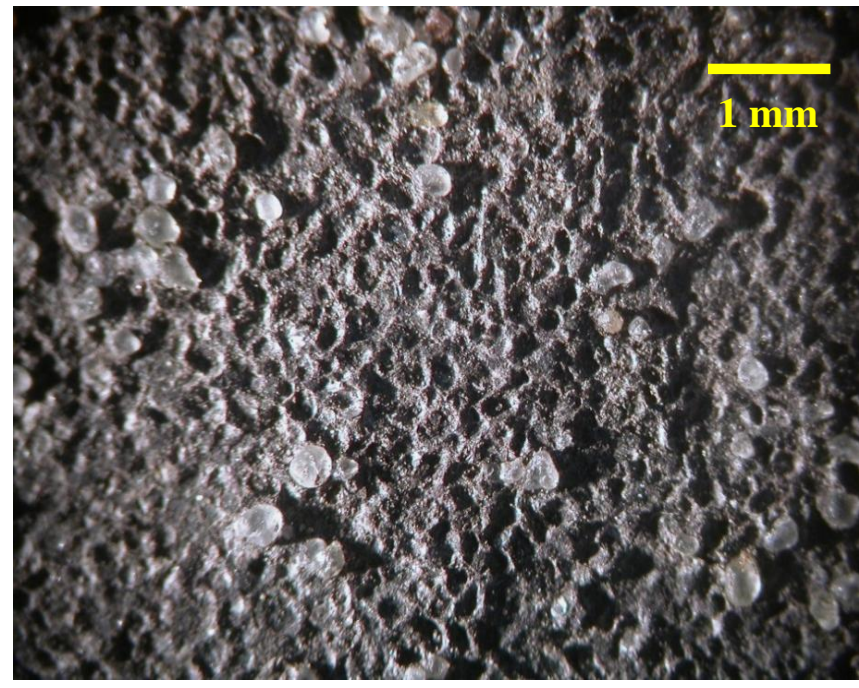

(a)

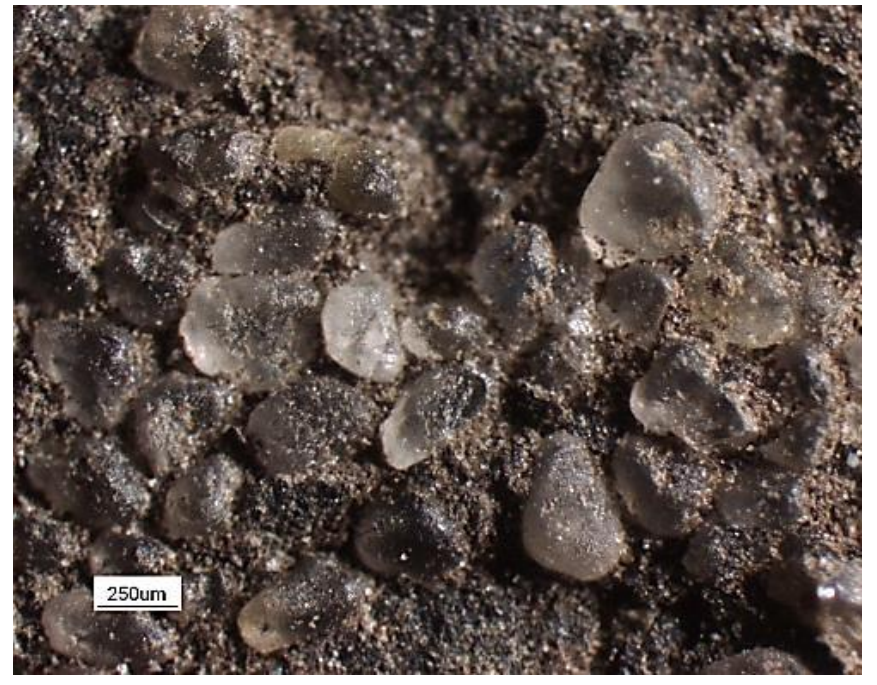

(b)

Fig. 8-Microscopic images of $40 / 70$ mesh sand embedment into the Barnett shale fracture surface after the conductivity measurement by water. The closure stress was 4,000 psi.

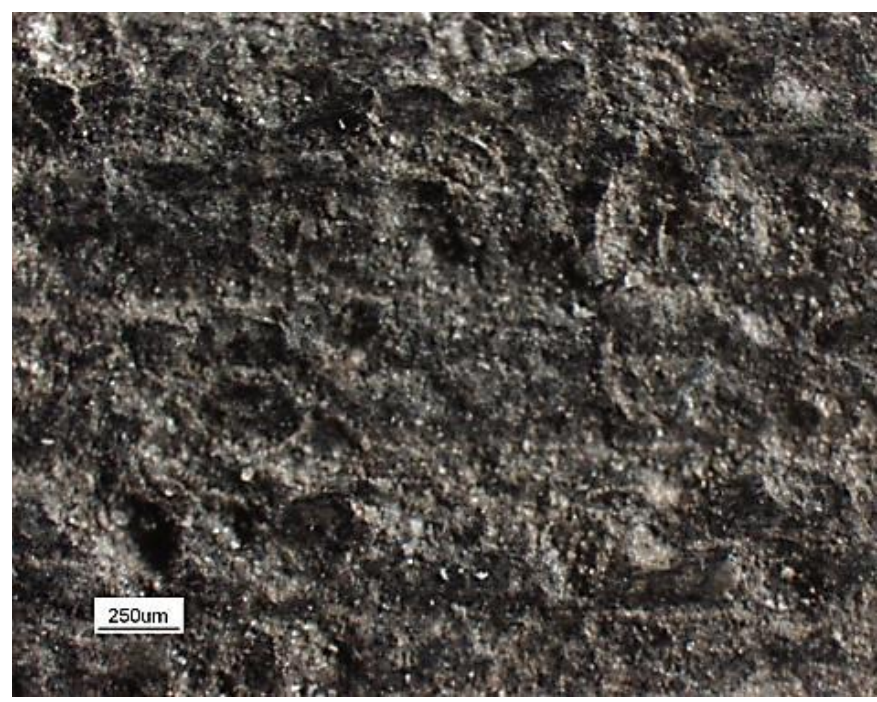

Fig. 9-Microscopic image of 40/70 mesh sand embedment into the Barnett shale fracture surface after the conductivity measurement by gas only. The closure stress was 4,000 psi. 


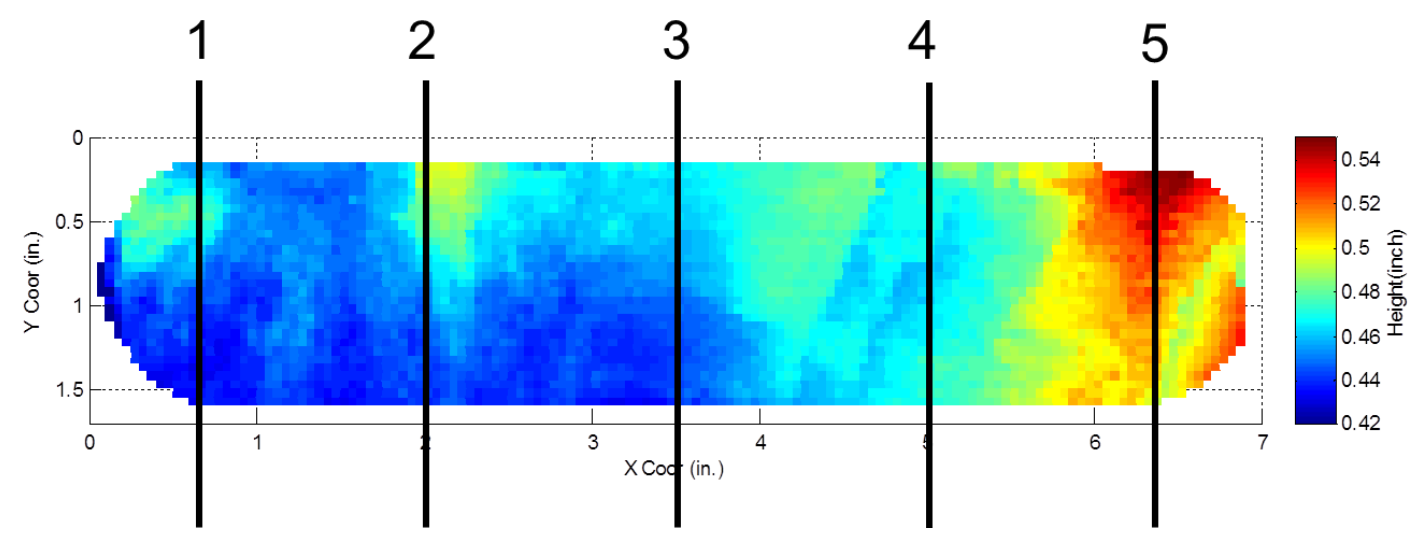

Fig. 10-Measurement locations on the shale fracture surface.

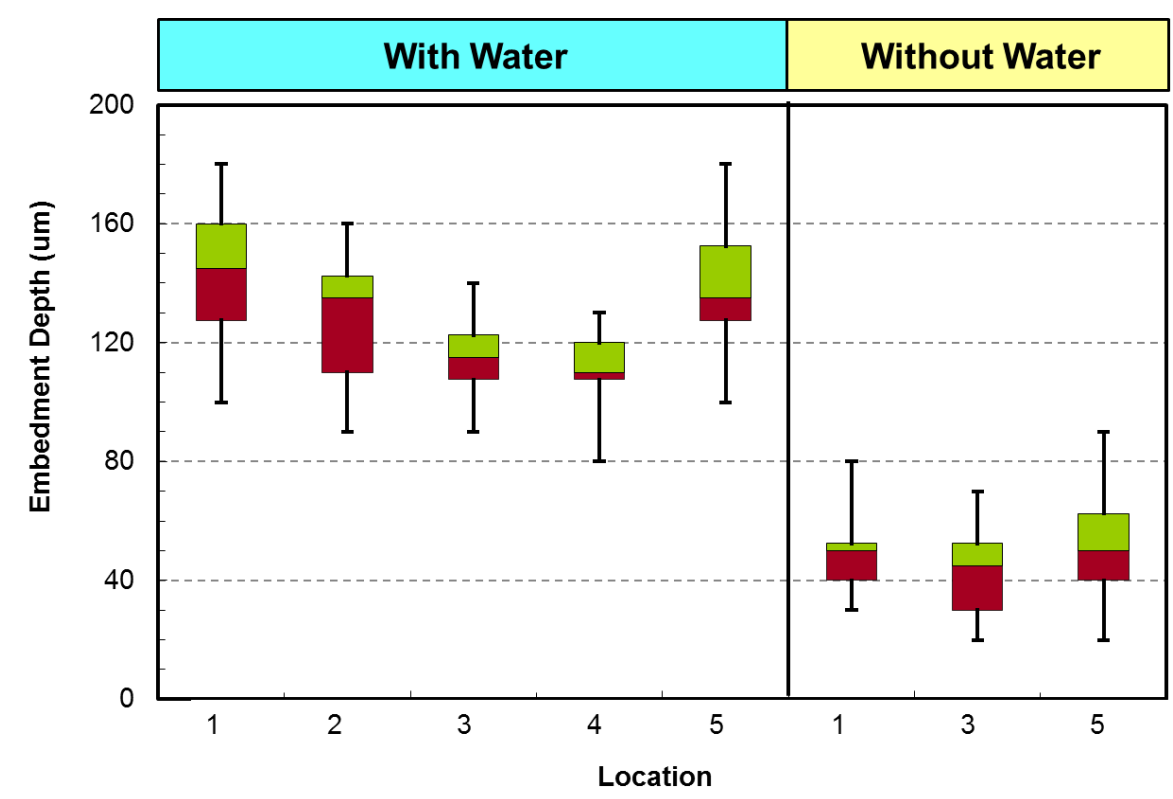

Fig. 11-Comparison of the embedment depth after a water test with the embedment depth after a dry gas test. 40/70 mesh sands were placed on both fractures. The boxplot shows the maximum, $75 \%, 50 \%, 25 \%$ and the minimum embedment depths. The closure stress was 4,000 psi. 


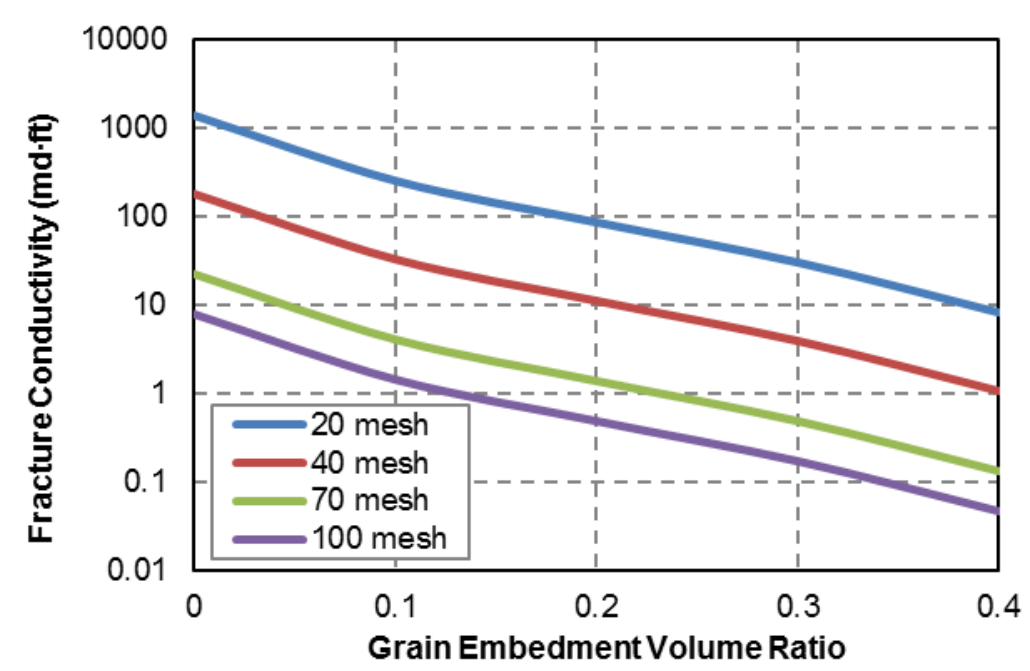

(a) One layer of proppants

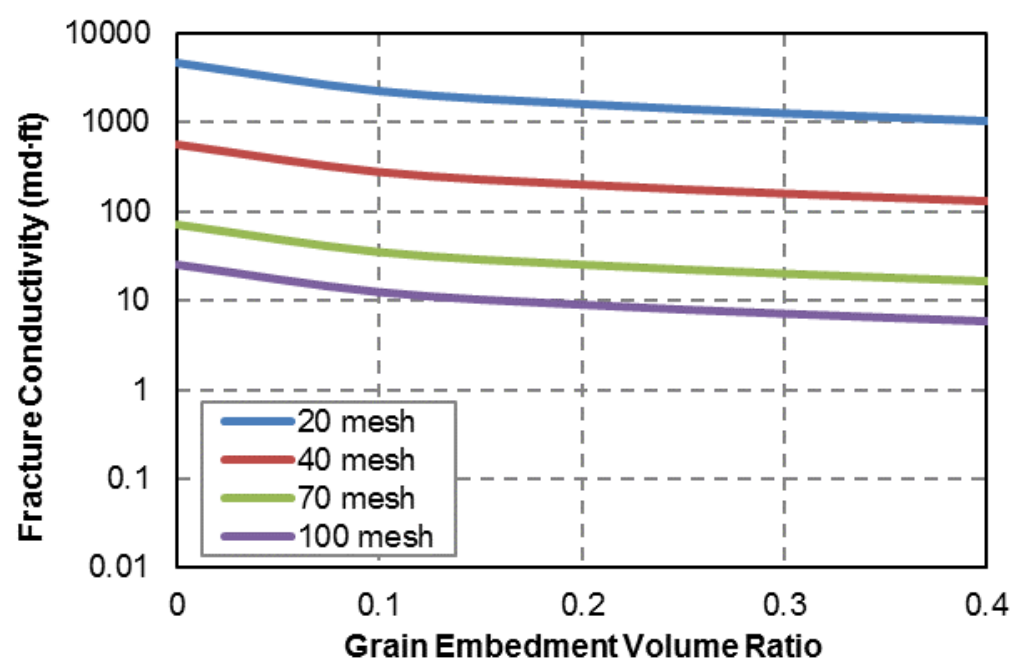

(b) Two layers of proppants

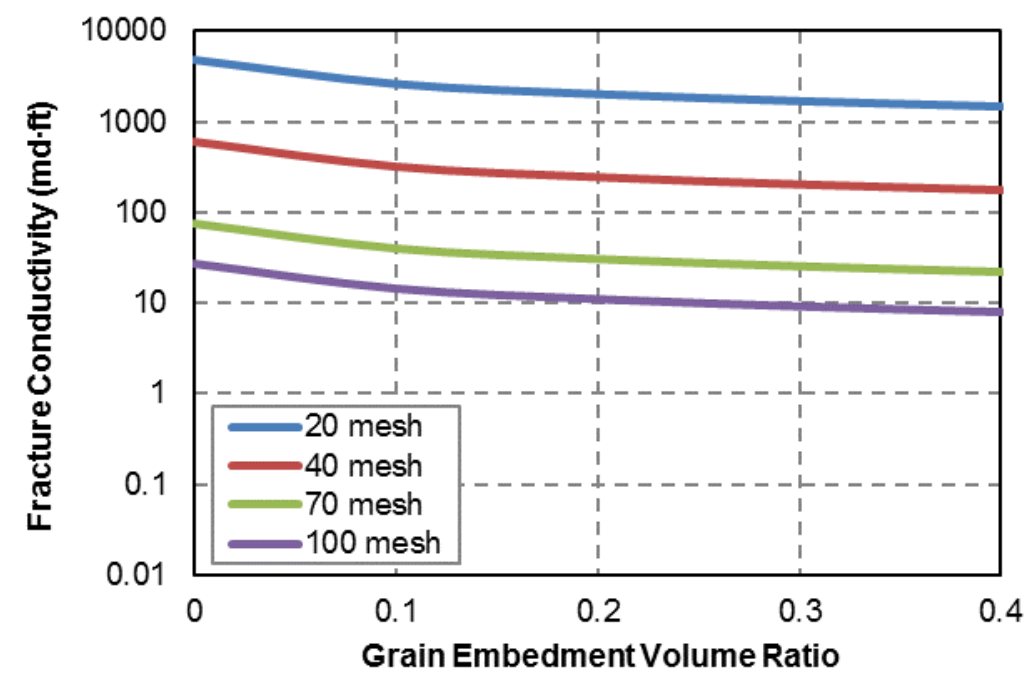

(c) Three layers of proppants

Fig. 12-Fracture conductivities as a function of grain embedment volume ratio, proppant size and the number of proppant layers. 


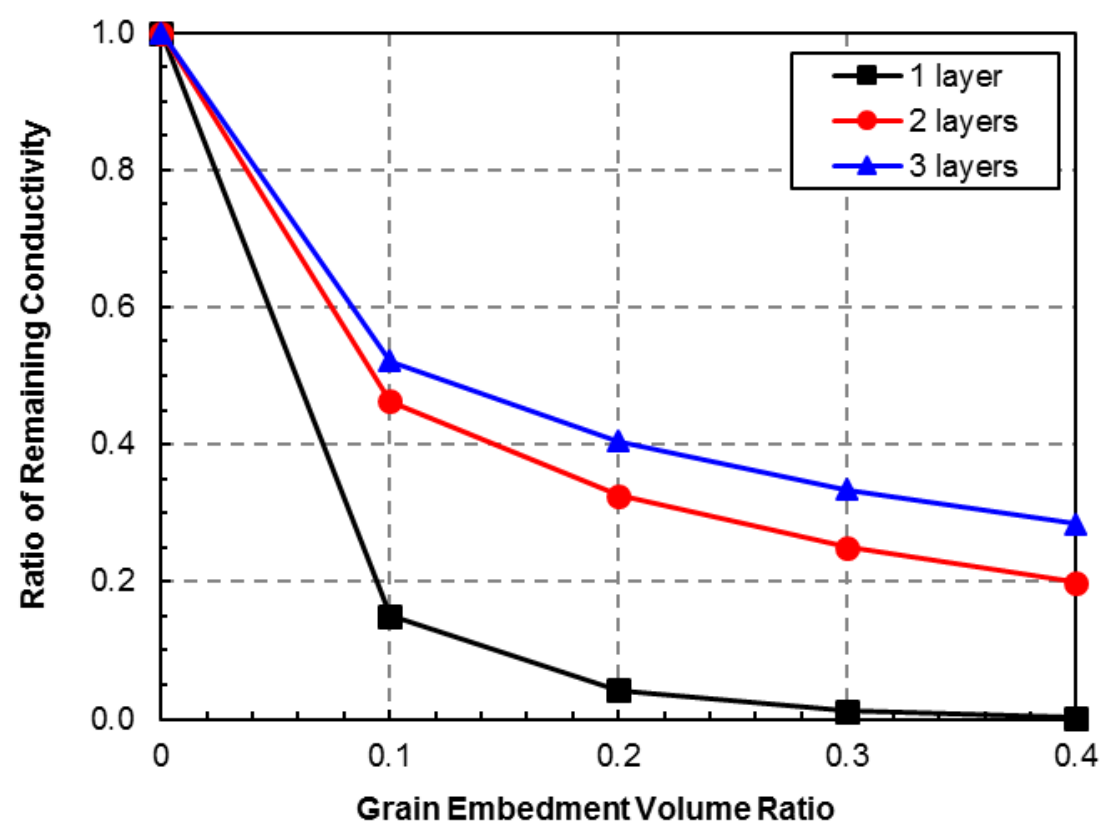

Fig.13-Grain embedment volume ratio versus ratio of remaining fracture conductivities for various proppant layers.

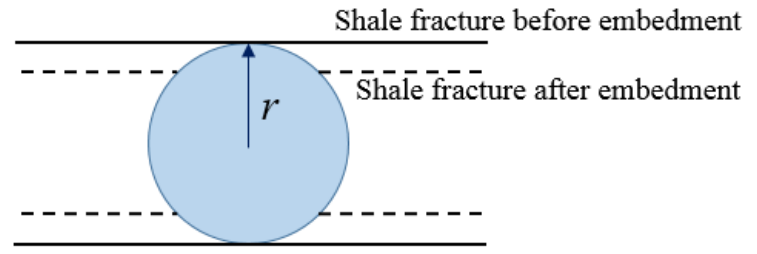

(a)

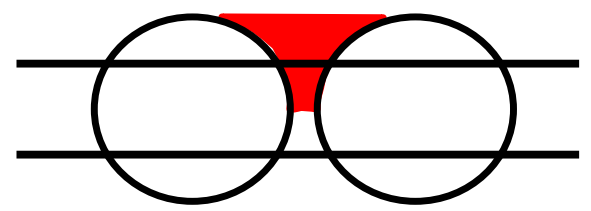

(b)

Fig.14-Flow area of the proppant layer close to the fracture walls. 